\title{
Association of hand and knee osteoarthritis: evidence for a polyarticular disease subset
}

Rosemarie Hirsch, Margaret Lethbridge-Cejku, William W Scott Jr, Ralph Reichle, Chris C Plato, Jordan Tobin, Marc C Hochberg

\begin{abstract}
Objective-To examine the association between hand and knee osteoarthritis (OA) in a community based population. Methods-Radiographs of 695 participants aged $\geq 40$ years in the Baltimore Longitudinal Study of Aging were read for changes of $O A$, using Kellgren-Lawrence grade $\geq 2$ as the case definition.

Results-Logistic regression analyses, adjusting for age, gender and body mass index, revealed a significant association between OA in the knee and the following joint groups: distal and proximal interphalangeal (DIP, PIP) and Hand2 (OA in two or more hand joint groups) for grade 2-4 and grade 3-4 disease, and the first carpometacarpal (CMC1) joint for grade 3-4 disease.

Conclusion-There is an association between $O A$ in hand sites and the knee. The strength of the associations increases with increasing disease severity. For the PIP site, there is a trend toward increasing strength of association for increasing numbers of affected joints and bilateral disease.
\end{abstract}

(Ann Rheum Dis 1996; 55: 25-29)

Generalised osteoarthritis (GOA) was reported as early as 1805 and was re-emphasised in 1952 by Kellgren and Moore. ${ }^{1}$ In 1969, Lawrence described radiographic GOA, a polyarticular subset of osteoarthritis (OA), in a population based sample from Leigh and Wensleydale, England. ${ }^{2}$ Two criteria were used for case definition: either three or more, or five or more joint groups with grade 2-4 OA (as defined in the Atlas of Standard Radiographs), ${ }^{3}$ among the joint groups visible on radiographs from the following sites: hand, foot, knee, pelvis, and cervical and lumbar spine. The concept of GOA was validated in other population based studies using radiographically defined OA, ${ }^{4}$ however none of the earlier studies reported the association of OA between specific joint groups. More recently, the co-occurrence of $\mathrm{OA}$ at two of three major OA sites (hands, knees, and hips) was examined in a clinic based population in whom OA was defined by radiographs and clinical symptoms. ${ }^{5}$ The only significant association was found between knee and hand $O A$ in women.
The purpose of this study was to determine if the association between radiographic hand and tibiofemoral knee OA occurrred more often than that which could be attributed to chance alone, after adjusting for age, which is the strongest known risk factor for OA, and body mass index, as a measure of obesity, which is a risk factor for radiographic OA in some joint sites.

\section{Subjects and methods} STUDY POPULATION

All subjects in this study were participants in the Baltimore Longitudinal Study of Aging (BLSA), a multidisciplinary research project conducted at the Gerontology Research Center, National Institute on Aging in Baltimore, Maryland. The continuing research project began in 1958 and was limited to male participants until 1978, when women began to be enrolled. Participants are community dwelling volunteers of middle to upper socioeconomic status, who are evaluated at two year intervals. Radiographs of the hands have been taken quadrennially since inception of the research project, and knee radiographs were added to the examination procedure in 1985 . Ninety six percent of the BLSA participants are white; they were aged from 18 to 93 years at entry to the study. This paper reports a study of a population (referred to hereafter as the study population) limited to white participants (426 men and 269 women aged 40 years and above) who had bilateral hand and knee radiographs, obtained at the same visit, from 1985 to 1991 .

\section{RADIOGRAPHS AND DEFINITIONS}

Bilateral posteroanterior hand and bilateral standing anteroposterior tibiofemoral knee radiographs were read for the presence of OA as described in the Atlas of Standard Radiographs. ${ }^{3}$ The five point Kellgren-Lawrence scales used (0-4) were: grade $0=$ normal; grade 1 = questionable; grade $2=$ mild; grade 3 = moderate; grade $4=$ severe. Definite OA was defined as Kellgren-Lawrence grade 2 or higher, present in at least one joint of a given group. ${ }^{6}$

Radiographs of each joint site were read by a separate radiologist (hand: WWS; knee: RR), blinded to the subject. Previously obtained inter-reader (and intra-reader) intra-class correlations for these investigators and joint 
sites were $0.74(0.80)$ and $0.68(0.87)$, respectively. ${ }^{78}$

The following joint groups were examined: the knees, and the distal and proximal interphalangeal (DIP, PIP) and first carpometacarpal (CMC1) joints of the hands. For convenience, the occurrence of definite $O A$ in at least two of the three hand joint groups was termed Hand2.

Anthropometric measurements were made of height $(\mathrm{m})$ and body weight $(\mathrm{kg})$. Obesity was measured as body mass index (BMI) $\left(\mathrm{kg} /(\mathrm{m})^{2}\right)$.

\section{DATA ANALYSIS}

Separate multiple logistic regression analyses were used to estimate the odds ratio for the association of knee $\mathrm{OA}$ with $\mathrm{OA}$ at each hand site: knee OA was the dependent variable; the independent variables were BMI, which is continuous; age, which is ordinal (by decade); gender, and OA at each hand site, which are dichotomous. The reference group for all of the knee $O A$ and hand site $O A$ association analyses was no involvement of the respective hand sites. Interaction terms consisted of combinations of the independent variables. For the DIP and PIP hand sites, the contribution of increasing numbers of affected digits, and unilateral or bilateral disease was compared with no affected digits at the respective site.

Two sets of dummy variables were created: the first set was to test the association of interphalangeal (IP) and knee OA in two joint increments of affected IP joints; the second set was to test the association of IP and knee OA using two groupings of unilateral and bilateral IP OA. In group I, the dummy variables were created for unilateral or bilateral OA of one or more affected digits, respectively. In group II, hand $\mathrm{OA}$ was further broken down into the following dummy variables: one affected digit; more than one affected digit unilateral disease: one affected digit on each hand; bilateral hand joint OA, two or more affected digits present on at least one hand. The dummy variables in each group were analysed using no affected hand joint digits as the reference.

Logistic regression analyses were performed using Statistical Analysis Systems, Release $6 \cdot 07$, SAS Institute, Cary, North Carolina.

\section{Results}

The study population consisted of 426 white men and 269 white women, aged $40-89$ years (mean 64 (SD 12) years for men; mean 65 (13) years for women). Figure 1 shows the age and gender specific prevalence of grade 2-4 OA for each joint group studied. The DIP joint was the most frequent site of OA involvement in both genders and all age groups. Hand OA was significantly more prevalent in women at age 60 and older at each hand site, especially the CMC1. The prevalence of grade 2-4 knee OA was comparable in men and women. Figure 1 also demonstrates the strong association between increasing age and increasing $O A$ prevalence at each joint site.

Figure 2 shows the overall prevalence of grade 2-4 polyarticular OA by sites involved. The combination of DIP and knee involvement had the greatest prevalence: $29.4 \%$ for men and $32.6 \%$ for women. The combination of three joint groups (Hand2 plus knee OA) was not uncommon, with a prevalence of $22.0 \%$ for men and $26.0 \%$ for women. An age associated increase in grade 2-4 hand and knee polyarticular OA occurred at significance levels of $\mathrm{p} \leq 0.0001$, regardless of the hand site involved
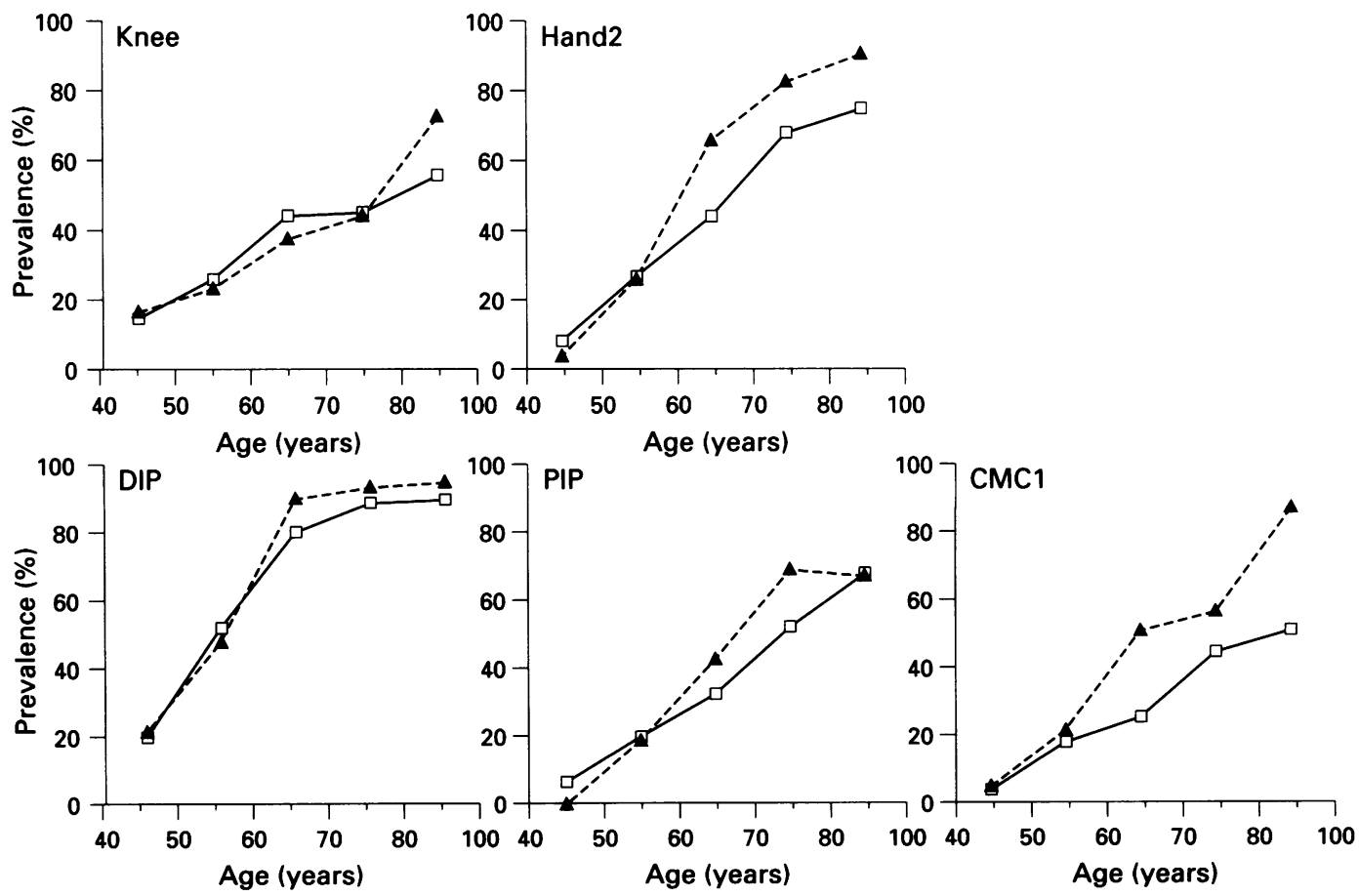

Figure 1 Age and gender specific prevalence of radiographic changes of grade 2-4 osteoarthritis in the knee, two or more hand joint groups (Hand2), distal and proximal interphalangeal (DIP, PIP), and carpometacarpal (CMC1) joints. $\square=$ Men; $\Delta=$ women. 


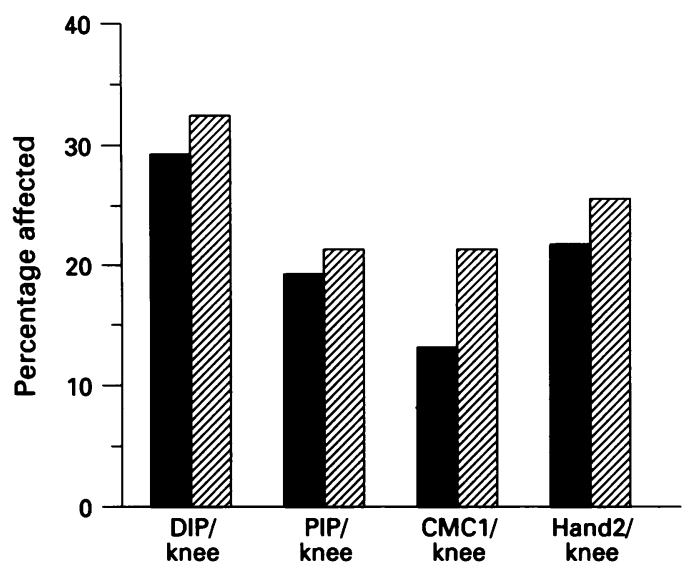

Figure 2 Proportion of subjects with radiographic changes of grade 2-4 osteoarthritis at multiple sites in men ( 1 ) and women ( $\square)$. Abbreviations as in figure 1.

(data not shown). The crude odds ratios, unadjusted for age, gender or BMI, showed significant association at all sites (table 1).

When data for both genders are combined, an association between grade 2-4 knee and hand OA was seen in this population at all joint sites, except the $\mathrm{CMC1}$, even after adjusting for the effects of age, BMI and gender

Table 1 Crude odds ratios (OR) and $95 \%$ confidence intervals (CI) for the association of grade 2-4 hand and knee osteoarthritis derived from multiple logistic regression analyses

\begin{tabular}{ll}
\hline foint groups & $O R(95 \%$ CI) \\
\hline Knee and DIP & $3.23(2.21 \text { to } 4 \cdot 74)^{\star \star \star}$ \\
Knee and PIP & $2.87(2.08 \text { to } 3.95)^{\star \star \star}$ \\
Knee and CMC1 & $2 \cdot 12(1.53 \text { to } 2 \cdot 92)^{\star \star \star}$ \\
Knee and Hand2 & $4.67(2.99 \text { to } 7 \cdot 29)^{\star \star \star}$ \\
\hline Signifis
\end{tabular}

Significance of association: ${ }^{\star \star \star} p<0.001$.

Table 2 Age adjusted odds ratios (OR), and age and BMI adjusted $O R$, and 95\% confidence intervals (CI) for the association of grade 2-4 hand and knee osteoarthritis derived from multiple logistic regression analyses

\begin{tabular}{llll}
\hline foint groups & OR $(95 \% C I)$ & & \\
\cline { 2 - 4 } & Combined & Men & Women \\
\hline Age adjusted data & & & \\
Knee and DIP & $1.85(1.20 \text { to } 2.84)^{\star \star}$ & $1.63(0.97$ to 2.74$)$ & $2.41(1.09 \text { to } 5.32)^{\star}$ \\
Knee and PIP & $1.87(1.31 \text { to } 2.66)^{\star \star \star}$ & $2.18(1.39 \text { to } 3.41)^{\star \star \star}$ & $1.41(0.78$ to 2.53$)$ \\
Knee and CMC1 & $1.33(0.93$ to 1.92$)$ & $1.28(0.80$ to 2.05$)$ & $1.36(0.76$ to 2.46$)$ \\
Knee and Hand2S & $2.43(1.44 \text { to } 4.13)^{\star \star}$ & $2.28(1.23 \text { to } 4.21)^{\star \star}$ & $3.02(1.04 \text { to } 8.78)^{\star}$ \\
Age and BMI adjusted data & & & \\
Knee and DIP & $1.71(1.10 \text { to } 2.65)^{\star}$ & $1.56(0.92$ to 2.63$)$ & $2.11(0.94$ to 4.74$)$ \\
Knee and PIP & $1.76(1.23 \text { to } 2.53)^{\star \star}$ & $2.03(1.29 \text { to } 3.19)^{\star \star}$ & $1.39(0.76$ to 2.55$)$ \\
Knee and CMC1 & $1.32(0.91$ to 1.91$)$ & $1.27(0.79$ to 2.04$)$ & $1.38(0.75$ to 2.52$)$ \\
Knee and Hand2S & $2.16(1.26 \text { to } 3.69)^{\star \star}$ & $2.09(1.12 \text { to } 3.90)^{\star}$ & $2.50(0.83$ to 7.48$)$ \\
\hline
\end{tabular}

tAdjusted for gender. $\$$ Reference group is no hand joint involvement.

Significance of associations: ${ }^{\star} p<0.05 ;{ }^{\star \star} p<0.01 ;{ }^{\star \star} \mathrm{p}<0.001$.

Table 3 Age adjusted odds ratios (OR), and age and BMI adjusted $O R$, and 95\% confidence intervals (CI) for the association of grade 3-4 hand and knee osteoarthritis derived from multiple logistic regression analyses

\begin{tabular}{|c|c|c|c|}
\hline \multirow[t]{2}{*}{ foint groups } & \multicolumn{3}{|l|}{ OR $(95 \% C I)$} \\
\hline & Combinedt & Men & Women \\
\hline $\begin{array}{l}\text { Age adjusted data } \\
\text { Knee and DIP } \\
\text { Knee and PIP } \\
\text { Knee and CMC1 } \\
\text { Knee and Hand2\$ }\end{array}$ & $\begin{array}{l}6.84(1.39 \text { to } 33.64)^{\star} \\
5.55(2.11 \text { to } 14.60)^{\star \star \star} \\
3.63(1.67 \text { to } 7.90)^{\star \star} \\
16.41(3.28 \text { to } 82.02)^{\star \star \star}\end{array}$ & $\begin{array}{l}4.31(0.80 \text { to } 23.17) \\
3.11(0.91 \text { to } 10.69) \\
2.93(1.10 \text { to } 7.80)^{\star} \\
8.49(1.50 \text { to } 48.02)^{\star}\end{array}$ & $\begin{array}{l}\text { NC } \\
16 \cdot 64(2 \cdot 80 \text { to } 98 \cdot 90)^{\star \star} \\
5 \cdot 37(1 \cdot 38 \text { to } 20 \cdot 85)^{\star} \\
\text { NC }\end{array}$ \\
\hline $\begin{array}{l}\text { Age and BMI adjusted } \\
\text { Knee and DIP } \\
\text { Knee and PIP } \\
\text { Knee and CMC1 } \\
\text { Knee and Hand2S }\end{array}$ & $\begin{array}{l}\text { data } \\
7.62(1.52 \text { to } 38.63)^{\star} \\
5.16(1.92 \text { to } 13.87)^{\star \star} \\
4.10(1.83 \text { to } 9.19)^{\star \star \star} \\
19.51(3.78 \text { to } 100.74)^{\star \star \star}\end{array}$ & $\begin{array}{l}6.51(0.99 \text { to } 42.82) \\
2.45(0.67 \text { to } 8.93) \\
3.48(1.24 \text { to } 9.79)^{\star} \\
9.58(1.61 \text { to } 57.09)^{\star}\end{array}$ & $\begin{array}{l}\mathrm{NC} \\
17 \cdot 55(2 \cdot 90 \text { to } 106 \cdot 12)^{\star \star} \\
5 \cdot 46(1 \cdot 41 \text { to } 21 \cdot 18)^{\star} \\
\mathrm{NC}\end{array}$ \\
\hline
\end{tabular}

(table 2). The gender specific odds ratios for polyarticular OA (derived from separate age and BMI adjusted logistic regression analyses for each gender), differed from each other in statistical significance at the knee plus PIP and Hand2 sites for grade 2-4 disease. However, these gender specific differences were not significant when interaction was tested in logistic regression analyses of the entire study population using the independent variables age, gender, $\mathrm{BMI}$, and hand site $\mathrm{OA}$, plus an interaction term incorporating gender and hand site OA (data not shown). Adjusting for BMI decreases the point estimates for almost all of the analyses; however, the significance of the hand and knee OA associations remained substantially the same (table 2 ). For grade 3-4 disease, the point estimates for association were greater throughout, especially for women, and were statistically significant for all hand sites when both genders were combined, even after adjustment for age and BMI (table 3 ).

Figure 3 presents data that suggest a trend of incremental increases in the odds ratio point estimates for association between increased numbers of affected interphalangeal joints and knee OA. For DIP OA, where only one digit was affected unilaterally or bilaterally, or more than one digit was affected unilaterally, there was no significant association with knee OA (table 4). However, there was a significant association between knee OA and bilateral DIP OA involving more than two digits. For PIP $\mathrm{OA}$, there was no significant association between unilateral disease of one or more digits and knee OA. However, bilateral disease involving at least one digit of each hand was significantly associated with knee OA.

\section{Discussion}

The main finding of this study is the association between radiographically defined hand joint and tibiofemoral knee $O A$ in a healthy, community dwelling population, after adjusting for age, gender, and BMI. The trends in age and gender specific prevalence of hand and knee OA sites in this study are similar to those reported in other population based studies of radiographic OA. ${ }^{469-15}$ In studies in which hand, feet, knee, hip, and spine radiographs were available, non-nodal GOA was slightly more common in men than in women, and nodal GOA and severity of OA at individual sites were more common in women. Grade 2-4 polyarticular OA at the DIP, PIP, $\mathrm{CMC1}$, and Hand2 plus knee OA sites had greater prevalences in women in our study (fig 2). However, associations of OA between specific joint groups were not reported in the earlier polyarticular OA studies ${ }^{2}$ and data concerning Heberden's nodes have not been analysed in the BLSA cohort.

Although we found a significant association between hand and knee OA in both men and women in our study, Cushnaghan and Dieppe found an association in women only. ${ }^{5}$ This difference may be attributable to the different composition of the study populations: healthy community volunteer compared with clinic 

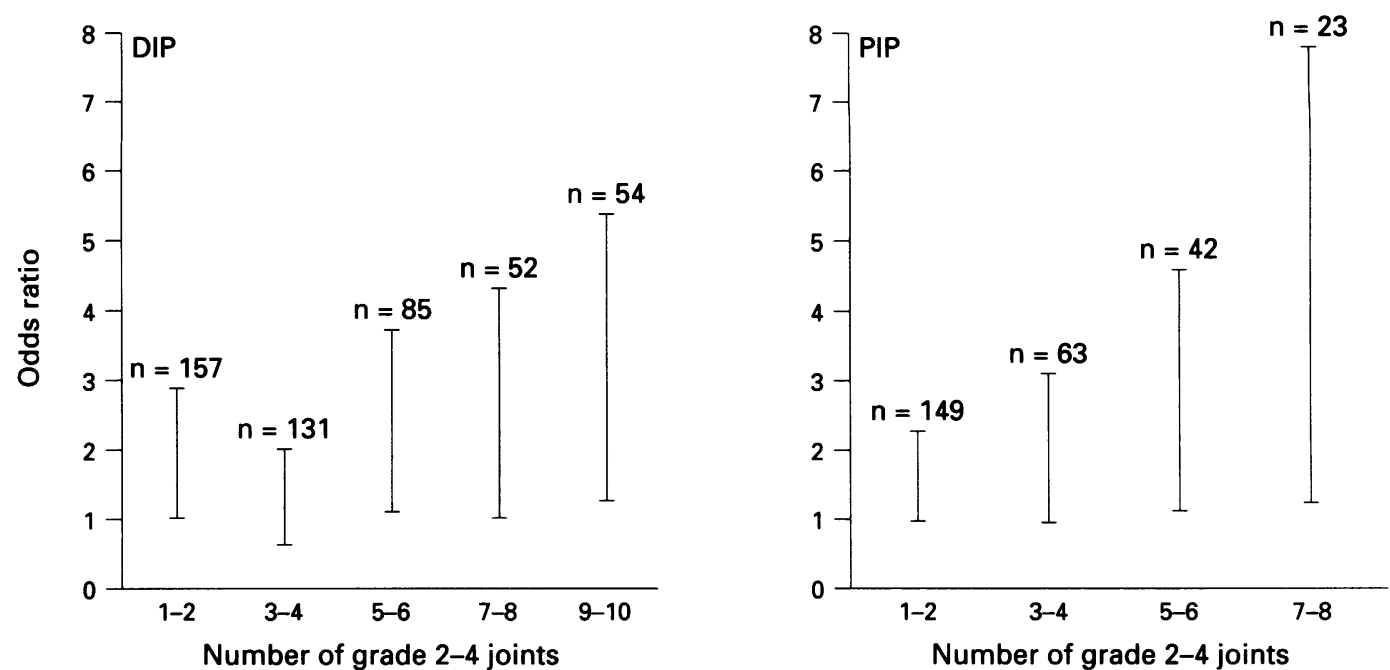

Figure 3 Odds ratios and confidence intervals of association for number of grade 2-4 affected DIP joints and grade 2-4 knee OA (left), and for number of grade 2-4 affected PIP joints and grade 2-4 knee OA (right). $\times=$ Point estimate.

based. Different case definitions (symptomatic radiographic disease versus radiographic disease) may also have contributed, as gender specific differences in symptom reporting have been documented. ${ }^{16}$ However, the possibility of a gender difference in the occurrence of polyarticular OA should not be disregarded. Although the differences in the gender specific odds ratios in our study did not achieve statistical significance when a gender-by-hand site interaction variable was added to the logistic regression model for the entire study population, there may not have been a sufficient number cases of polyarticular $O A$ in the younger and sometimes the eldest age strata to allow detection of an interaction. ${ }^{17}$ Investigation of the significance of this trend would require analysis of larger samples from the same or comparable populations.

The strengths of association for the various unilateral and bilateral DIP joint OA variables were comparable (table 4); the lack of significance for unilateral or bilateral single digit DIP OA, and multidigit unilateral OA, probably reflects the small numbers of affected participants. For PIP OA, there was a trend toward increasing association for numbers of joints involved and bilateral disease (fig 3, table 4). The wider confidence interval for one digit bilateral disease, overlapping that for bilateral disease with more than two digits, may account for the greater odds ratio point estimate of the former.

Table 4 Age and BMI adjusted odds ratios (OR) and $95 \%$ confidence intervals (CI) for the association of knee and single or multidigit hand osteoarthritis $(O A)$ derived from multiple logistic regression analyses

\begin{tabular}{|c|c|c|c|c|c|}
\hline \multirow{2}{*}{\multicolumn{2}{|c|}{$\begin{array}{l}\text { Analysis by dummy } \\
\text { variable group }\end{array}$}} & \multicolumn{2}{|l|}{$D I P$} & \multicolumn{2}{|l|}{$P I P$} \\
\hline & & OR $(95 \% C I)$ & $\begin{array}{l}\text { Number } \\
\text { in group }\end{array}$ & OR $(95 \% C I)$ & $\begin{array}{l}\text { Number } \\
\text { in group }\end{array}$ \\
\hline I. & $\begin{array}{l}\text { No OAS } \\
\geq 1 \text { digit unilateral } O A \\
\geq 1 \text { digit bilateral } O A\end{array}$ & $\begin{array}{l}1.73(1.01 \text { to } 2.95)^{\star} \\
1.70(1.07 \text { to } 2.70)^{\star}\end{array}$ & $\begin{array}{l}216 \\
119 \\
360\end{array}$ & $\begin{array}{l}1.45(0.93 \text { to } 2.24) \\
2.18(1.40 \text { to } 3.39)^{\star \star \star}\end{array}$ & $\begin{array}{l}418 \\
133 \\
144\end{array}$ \\
\hline II. & $\begin{array}{l}\text { No OAS } \\
1 \text { digit unilateral OA } \\
>1 \text { digit unilateral OA } \\
1 \text { digit bilateral OA } \\
\text { Bilateral OA with } \geq 2 \\
\text { digits on } \geq 1 \text { hand }\end{array}$ & $\begin{array}{l}1.74(0.97 \text { to } 3.12) \\
1.68(0.73 \text { to } 3.87) \\
1.79(0.88 \text { to } 3.63) \\
1.68(1.04 \text { to } 2.71)^{\star}\end{array}$ & $\begin{array}{r}216 \\
87 \\
32 \\
48 \\
312\end{array}$ & $\begin{array}{l}1.34(0.83 \text { to } 2.17) \\
1.81(0.83 \text { to } 3.93) \\
2.73(1.09 \text { to } 6.87)^{\star} \\
2.09(1.30 \text { to } 3.34)^{\star \star}\end{array}$ & $\begin{array}{r}418 \\
102 \\
31 \\
22 \\
122\end{array}$ \\
\hline
\end{tabular}

SReference group.

Significance of associations: ${ }^{\star} p<0.05 ;{ }^{\star \star} p<0.01 ;{ }^{\star \star \star} p<0.001$
The lack of lateral or skyline views of the knee for assessment of patellofemoral joint $\mathrm{OA}$ is a limitation of this study, and may have resulted in misclassification of some of the participants to the group without knee OA. ${ }^{18}$ Another constraint of the study is the use of the Kellgren-Lawrence OA grading system, which ranks osteophytes over joint space narrowing for assigning grade severity. ${ }^{3}$ Despite recent questions regarding the significance of osteophytes in disease progression, ${ }^{19-23}$ the KellgrenLawrence scale remains the standard for case definition. The Kellgren-Lawrence scale was, furthermore, used to attain grading system comparability with earlier polyarticular OA studies.

In summary, this study examined the association between radiographic changes of hand and knee OA in a healthy, community dwelling population. The findings include significant associations between radiographic $\mathrm{OA}$ at the DIP, PIP, and CMC1 joints, and the knee. The strength of these associations increased with disease severity and, for the PIP site, there was a trend toward increasing strength of association with increasing numbers of affected joints and bilateral disease.

This study was supported in part by a grant from the Arthritis Foundation, Maryland Chapter.

1 Kellgren J H, Moore R. Generalized osteoarthritis and heberden's nodes. BMF 1952; 1: 181-7.

2 Lawrence J S. Generalized osteoarthritis in a population sample. Am f Epidemiol 1969; 90: 381-9.

3 The Department of Rheumatology and Medical Illustration, University of Manchester and Manchester Royal Infirmary and the Empire Rheumatism Council's Field Unit. Atlas of Standard Radiographs of Arthritis. In: The epidemiology of chronic rheumatism: volume II. Philadelphia: FA Davis Company, 1963.

4 Acheson R M, Collart A B. New Haven survey of joint diseases. Ann Rheum Dis 1975; 34: 379-87.

5 Cushnaghan J, Dieppe P. Study of 500 patients with limb joint osteoarthritis. I. Analysis by age, sex, and distribution of symptomatic joint sites. Ann Rheum Dis 1991; 50: 8-13.

6 Kellgren J H, Lawrence J S. Osteo-arthrosis and disk degeneration in an urban population. Ann Rheum Dis degeneration in an

7 Kallman D A, Wigley F M, Scott W W Jr, Hochberg M C, Tobin J D. New radiographic grading scales for osteoarthritis of the hand. Arthritis Rheum 1989; 32: 1584-90

8 Scott W W Jr, Lethbridge-Cejku M, Reichle R, Wigley F M, Tobin J D, Hochberg M C. Reliability of grading scales for individual radiographic features of osteoarthritis of the knee. Invest Radiol 1993; 28: 497-501. 
9 Lawrence J S. Rheumatism in populations. London: William Heinemann Medical Books Ltd, 1977.

10 Van Saase J, Van Romunde L, Cats A, Vandenbroucke J, Valkenburg H. Epidemiology of osteoarthritis: Zoetermeer survey. Comparison of radiological osteoarthritis in a Dutch population with that in 10 other populations. Ann Rheum Dis 1989; 48: 271-80.

Ann Rheum Dis 1989; 48: $271-80$.
11 Engel A, Burch T A. Osteoarthritis in adults by selected demographic characteristics, 1960-62. Vital and Health
Statistics, series 11, No 20. DHEW publication No. (PHS) Statistics, series 11, No 20. DHEW publication No. (PHS)
66-62094. Hyattesville, MD: National Center for Health Statistics, 1966.

12 Maurer K. Basic data on arthritis; knee, hip and sacroiliac joints in adults ages 25-74 years: United States, 1971-1975. Vital and Health Statistics, series 11, No 213. DHEW publication No (PHS) 79-1661. Hyattesville, MD: National Center for Health Statistics, 1979.

13 Lethbridge-Cejku M, Tobin J D, Scott W W Jr, Reichle R, Plato C C, Hochberg M C. The relationship of age and gender to prevalence and pattern of radiographic changes of osteoarthritis of the knee: Data from caucasian participants in the Baltimore longitudinal study of aging.

14 Felson D T, Naimark A, Anderson J, Kazis L, Castelli W, Meenan R F. The prevalence of knee osteoarthritis in the elderly. Arthritis Rheum 1987; 30: 914-8.

15 Bagge E, Bjelle A, Eden S, Svanborg A. Factors associated with radiographic osteoarthritis: results from the popu- lation study 70-year-old people in Goteborg. $\mathcal{F}$ Rheumatol 1991; 18: 1218-22.

16 Cunningham L S, Kelsey J L. Epidemiology of musculoskeletal impairments and associated disability. $A m \mathcal{F}$ Public Health 1984; 74: 574-9.

17 Kahn H A, Sempos C T. Statistical methods in epidemiology. New York: Oxford Press, 1989; 115-6.

18 McAlindon T E, Snow S, Cooper C, Dieppe P A. Radiographic pattern of osteoarthritis of the knee joint in the community: the importance of the patellofemoral joint. Ann Rheum Dis 1992; 51: 844-9.

19 Kallman D A, Wigley F M, Scott W W Jr, Hochberg M C, Tobin J D. New radiographic grading scales for osteoarthritis of the hand, reliability for determining prevalence and progression. Arthritis Rheum 1989; 32: 1584-91.

20 Altman R D, Fries J F, Bloch D A, et al. Radiographic assessment of progression in osteoarthritis. Arthritis Rheum 1987; 30: 1214-25.

21 Schouten J S A G, van den Ouweland F A, Valkenburg H A. A 12 year follow up study in the general population on A 12 year follow up study in the general population on
prognostic factors of cartilage loss in osteoarthritis of the prognostic factors of cartilage loss in osted
knee. Ann Rheum Dis 1992; 51: 932-7.

22 Dougades $M$, Gueguen A, Nguyen $M$, et al. Longitudinal radiologic evaluation of osteoarthritis of the knee. f Rheumatol 1992; 19: 378-84.

23 Spector T D, Cooper C. Radiographic assessment of osteoarthritis in population studies: whither Kellgren and Lawrence? Osteoarthritis and Cartilage 1993; 1: 203-6. 
assumptions with respect to scale interpretation and statistical analyses.

G STUCKI S STUCKI P BRÜHLMANN B A MICHEL

Department of Rheumatology and Physical Medicine, University Hospital, Zürich, Switzerland

1 Wright B D. Solving measurement problems with the Rasch model. $\mathcal{F}$ Educ Res 1977; 14: with the

2 Silverstein B, Fisher W P, Kilgore K M, Harley J P, Harvey R F. Applying psychometric criteria to functional assessment in medical rehabilitation: II. Defining interval measures. Arch Phys Med Rehabil 1992; 73: 507-18.

3 Merbitz C, Morris J, Grip J C. Ordinal scales and foundations of misinference. Arch Phys Med Rehabil 1989; 70: 308-12.

\section{Epidemiology of adult Still's disease}

We read with interest the study by MagadurJoly and colleagues about the epidemiology of adult Still's disease (ASD) published recently in Annals. ${ }^{1}$ We would like to describe a patient who was significantly older than the age incidence mentioned in their study and posed considerable diagnostic difficulty.

A 66 year woman was referred urgently by her general practitioner with a two week history of sore throat, fever, weight loss, arthralgia/myalgia, and a rash. Apart from a history of hypertension she had previously been well.

When examined, she had a non-suppurative pharyngitis, a generalised polyarthritis with bilateral knee joint effusions and wrist and ankle joint synovitis bilaterally. She had an erythematous macular rash affecting her arms, legs, and trunk. She was pyrexial, with a temperature of $40^{\circ} \mathrm{C}$. There was no obvious site of infection. Examination of the abdomen was normal; in particular, there was no hepatosplenomegaly. Investigation revealed erythrocyte sedimentation rate $123 \mathrm{~mm} / 1 \mathrm{st}$ h, haemoglobin $12.5 \mathrm{~g} / \%$, leucocyte count $28.6 \times 10^{9} / 1$ (differential count, $94 \%$ polymorphs), mildly increased concentrations of urea and creatinine $(16.6 \mathrm{mmol} / \mathrm{l}$ and 169 $\mu \mathrm{mol} / 1$, respectively), and normal liver function. Throat swab, blood cultures, and midstream urine were negative. Antistreptolysin $\mathrm{O}$ was normal. Echocardiography, electrocardiogram, and chest radiograph were normal. She was negative for rheumatoid factor, antinuclear factor and antineutrophil cytoplasmic antibodies on two occasions. Serum ferritin concentration was $17952 \mu \mathrm{g} / \mathrm{l}$ (normal range 15-200).

Over the next two weeks, the patient remained pyrexial, with her temperature peaking consistently in the evenings with recrudescence of her rash. Her joint symptoms initially responded to nonsteroidal anti-inflammatory agents, but she continued to be pyrexial. Her temperature persisted despite administration of aspirin, and she was prescribed prednisolone enteric $60 \mathrm{mg} /$ day, with resolution of the rash and pyrexia.

A diagnosis of ASD was made on the basis of the clinical features and exclusion of other pathology. She was discharged home, taking steroids and aspirin, and on subsequent review in clinic was greatly improved, with almost complete resolution of her rash and fever.

This patient illustrates several important clinical points, not stressed in the article published by Magadur-Joly and colleagues, but important for any future prospective studies on incidence. First, the diagnosis of ASD is often very difficult to make. Second, it is a diagnosis of exclusion. Third, given the rarity of the condition, diagnosis may be further delayed in patients of this age, though there are reports of ASD in this age group. ${ }^{23}$

Furthermore, the study by Magadur-Joly's group gave an approximation of the incidence of this disease in a French population obtained by written survey. We suspect that many cases of ASD are mild and go undiagnosed. Identification of such cases would therefore be difficult in any prospective study on ASD. Clearly, what is required is greater awareness of the disease and further research into its pathogenesis, in addition to prospective studies on incidence.

\section{CIARAN A DUNNE JEFF DAVIES Department of Rheumatology, Broomfield Hospital, Broomfield, Chelmsford, Essex CM1 SET,
United Kingdom}

1 Magadur-Joly G, Billaud B, Barrier J H, et al Epidemiology of adult Still's disease: estimate of the incidence by a retrospective study in west France. Ann Rheum Dis 1995; 54 587-90.

2 Wouters J M G W, van Rijswijk M H, van de Putte L B. Adult onset Still disease in the elderly: a report of two cases. $\mathcal{F}$ Rheumatol 1985; 12: 791-3.

3 Steffe L A, Cooke C L. Still's disease in a 70 year old woman. $\mathcal{F A M A} 1$ 1983; 249: 2062-3.

\section{AUTHORS' REPLY:}

Drs Dunne and Davies reported a case of adult Still's disease in an elderly patient and emphasised the difficulties of diagnosis, particularly in this age group. We share their opinion as to the difficulty of making a diagnosis of ASD, which is the reason why we used the criteria of Ohta et al (sensitivity $96 \%$; specificity $92 \%^{1}$ ) in all but one case. Nevertheless, in our experience diagnosis does not seem any more difficult in elderly patients: in our sudy we identified two patients who were 61 and 62 years old.

Drs Dunne and Davies suspect many cases of ASD to be mild. In our study we did not distinguish between mild ASD or full ASD, but required the symptoms to fit with the criteria of Ohta et al.

In conclusion, we agree that what is required is greater awareness of this disease, and we believe that making studies of its incidence is one approach to achieving progress towards that aim.

G MAGADUR-JOLY Service de Medicine Interne II, $C H U, B P 1005$ 44035 Nantes cedex 01, France

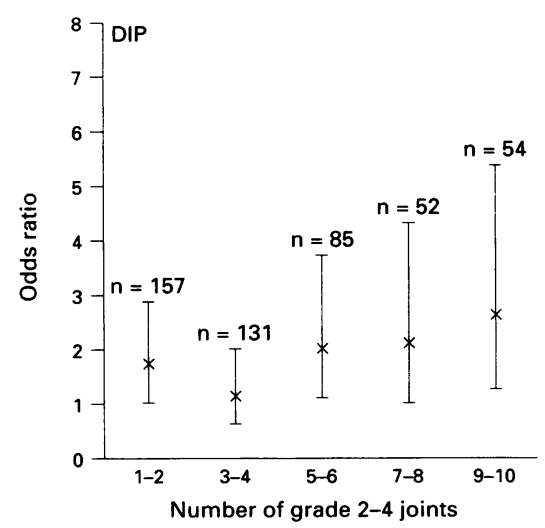

\section{LETTER TO THE EDITOR}

\section{Racial variation in rheumatoid arthritis}

MacGregor and colleagues ${ }^{1}$ reported a lower prevalence of rheumatoid arthritis in black Caribbeans than in white subjects in Manchester. There are grounds for supposing that one cause of RA is low testosterone levels. ${ }^{2}$ It has been reported that in the USA, black males have significantly higher testosterone levels than white males. ${ }^{3-5}$ A similar difference has been reported in the USA between (pregnant) black and white females. ${ }^{6}$ It seems likely that part of this racia variation of testosterone levels is not genetic. Meanwhile, it would be interesting to know whether there is racial variation in testosterone level in this country.

\section{WILLIAM H JAMES
MRC Mammalian Development Unit
Wolfson House University College London London NW1 $2 \mathrm{HE}$, United Kingdom}

1 MacGregor A J, Riste L K, Hazes J M W Silman A J. Low prevalence of rheumatoid arthritis in Black Caribbeans compared with Whites in inner city Manchester. Ann Rheum Dis 1994; 53: 293-7.

2 James W H. Rheumatoid arthritis, the contraceptive pill and androgens. Ann Rheum Dis 1993; 52: 470-4.

3 Ellis L, Nyborg H. Racial/ethnic variations in male testosterone levels: a probable contrimale testosterone levels: a probable contri-
bution to group differences in health. Steroids bution to group

4 Ross R, Bernstein L, Judd H, Hanisch R, Pike $M$, Henderson B. Serum testosterone levels in healthy young Black and White men. $\mathcal{f}$ Nat Cancer Inst 1986; 76: 45-48.

5 Hill P, Wynder E L, Garnes H, Walker A R P. Environmental factors, hormone status and prostatic cancer. Prev Med 1980; 9: 657-66.

6 Henderson B E, Bernstein L, Ross R K, Depue $\mathrm{R} H$, Judd $\mathrm{H}$ L. The early in utero oestrogen and testosterone environment of Blacks and Whites: potential effects on male offspring. $B$ f Cancer 1988; 57: 216-8.

7 James $\mathrm{W} H$. Causes of racial differences in testosterone levels of men. $\mathcal{f}$ Natl Cancer Inst 1993; 85: 506.

\section{Correction}

\section{Association of hand and knee}

osteoarthritis: evidence for a

polyarticular disease subset

Hirsch et al (Ann Rheum Dis 1996; 55: 25-29)

The publishers and typesetters apologise to the authors for errors that led to publication of a version of figure 3 that omitted point estimates shown in the orginal (below).

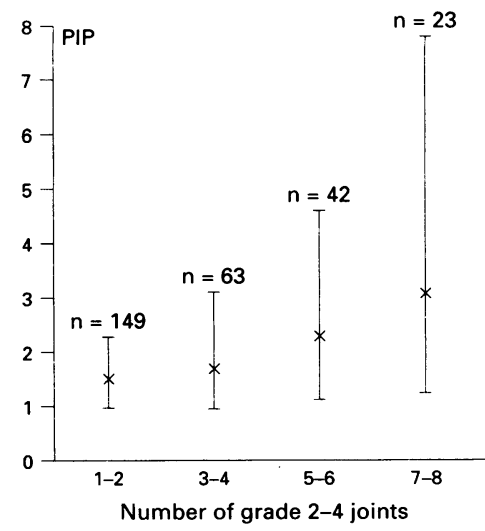

